\title{
Impact of Heat Rejection/Extraction Ratio of Ground-Source-Heat-Pump (GSHP) on Life-Cycle Energy Consumption
}

\author{
Qiong Guo1,a \\ ${ }^{1}$ Shanghai Aircraft Design and Research Institute, Commercial Aircraft Cooperation \\ of China (COMAC) \\ aemail: guoqiong@comac.cc
}

\begin{abstract}
Keywords: ground source heat pump (GSHP); life cycle analysis; heat balance
Abstract. The imbalance of heat rejection to and heat extraction from the ground has dramatic effect on the performance of a GSHP system, thus affects the heating and cooling energy usage of a building. A parametric study based on different heat rejection/extraction $(\mathrm{R} / \mathrm{E})$ ratio was conducted for a 20 -year life period to analyze the effect of such imbalance on the energy consumption increment. An analytical relationship between $\mathrm{R} / \mathrm{E}$ ratio and energy usage factor was concluded for current configuration of ground heat exchanger (GHX). A design guideline is recommended based on the spacing heating and cooling load ratio of a building.
\end{abstract}

\section{Introduction}

As an important renewable energy technology, ground-source heat pump (GSHP) is both energy efficient and environmental friendly. China is promising a $40 \% \sim 45 \%$ carbon emission intensity cut before Copenhagen Climate Conference 2009[1] and application of GSHP system to buildings is under the financial incentive [2]. According to 3859 GSHP projects investigated [3], GSHP systems are geographically distributed in almost all Chinese provinces. However, the difference between heat extraction and rejection affects both the life-cycle period and energy consumption of a system.

A short time step response factor model is proved to be sufficient and accurate in vertical ground loop heat exchanger modeling[4] and such model is adopted by energy simulation software such as Energyplus[5] and eQuest[6,7]. A typical high-rise office building located in Nanjing was selected. The building was designed to use GSHP to serve both heating and cooling demand. The study focuses on evaluating the feasibility of GSHP system on buildings in terms of heat injection/extraction ratio as well as the effect of operating time on energy performance of GSHP system.

\section{Building Energy Model}

The 17-story office building investigated is located in Nanjing. It is $42 \mathrm{~m} \times 30 \mathrm{~m}$ with floor to floor height of $3.2 \mathrm{~m}$ and floor to ceiling height of $2.7 \mathrm{~m}$. The basic construction of the building is as Table 1 .

Table 1. Building envelope configuration.

\begin{tabular}{llll}
\hline Exterior Wall & Roof & WWR & Window/doors \\
\hline 2x6 Metal Frame & Metal frame & E/W=20\% & Al frame \\
0.5" Fiber board sheathing & Shingle roofing & S/N=30\% & Glass type \#1 \\
R-11 batt. & 3" polystyrene & & \\
\hline
\end{tabular}

A GSHP system with vertical ground loop heat exchanger is utilized. The balance of the rejection/extraction $(\mathrm{R} / \mathrm{E})$ has great effect on the life-cycle period. The simulation was conducted first for the current location and then extended to other 8 cities in different typical climate zones of China. For each city, a 20-year simulation was conduction and the result was analyzed for each year in terms of energy consumption and $\mathrm{R} / \mathrm{E}$ ratio.

\section{Result and Discussion}

Both heating and cooling utilized electricity as source energy and the chiller is air-cooled for the condenser side. The result is as Figure 1. By adopting GSHP system, approximately $46 \%$ electricity can be saved. 


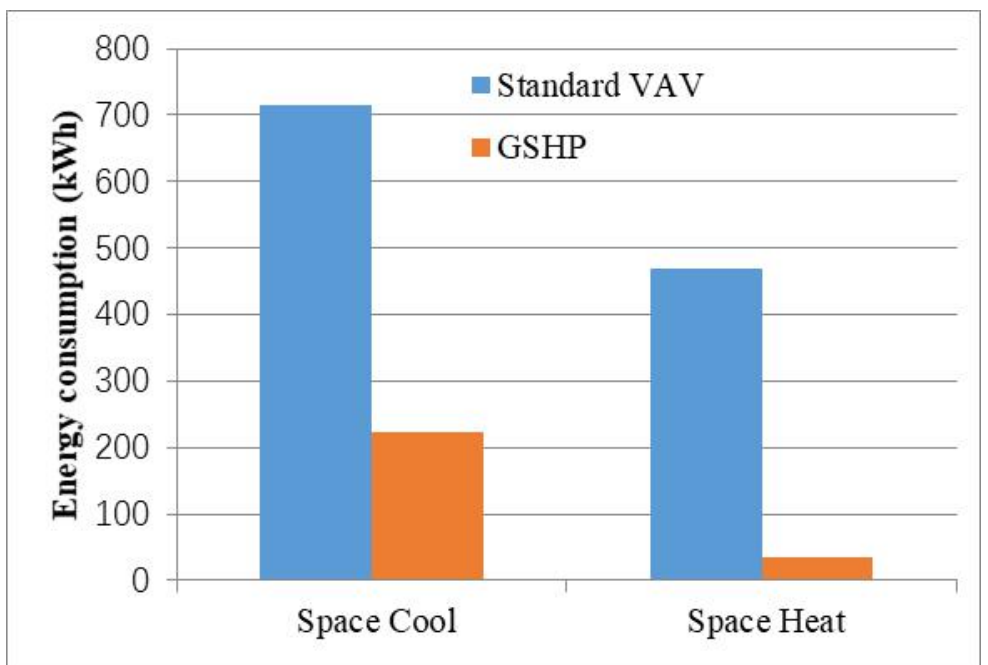

Figure 1. Comparison of energy consumption of different HVAC system.

The space heating and cooling energy usage increases with the increase of operating years. Table 2 shows a 21-year result where year 1 represents the $1^{\text {st }}$ year result. The result of following 20 years was normalized by the $1^{\text {st }}$ year energy use.

Table 2. Energy consumption result of the building varies with operating years.

\begin{tabular}{lllll}
\hline Operating yrs & Space H & Space C & Total(kWh) & Normalized \\
\hline 1 & 34,753 & 425,200 & 459,953 & 1 \\
2 & 33,380 & 446,326 & 479,706 & 1.042946 \\
3 & 33,025 & 453,749 & 486,774 & 1.058312 \\
4 & 32,786 & 458,767 & 491,553 & 1.068703 \\
5 & 32,610 & 462,467 & 495,077 & 1.076364 \\
6 & 32,470 & 465,425 & 497,895 & 1.082491 \\
7 & 32,357 & 467,805 & 500,162 & 1.08742 \\
8 & 32,261 & 469,821 & 502,082 & 1.091594 \\
9 & 32,178 & 471,571 & 503,749 & 1.095218 \\
10 & 32,105 & 473,117 & 505,222 & 1.098421 \\
11 & 32,040 & 474,502 & 506,542 & 1.101291 \\
12 & 31,986 & 475,642 & 507,628 & 1.103652 \\
13 & 31,937 & 476,676 & 508,613 & 1.105793 \\
14 & 31,892 & 477,628 & 509,520 & 1.107765 \\
15 & 31850.31 & 478509.6 & 510,360 & 1.109591 \\
16 & 31811.51 & 479331.6 & 511,143 & 1.111294 \\
17 & 31775.21 & 480101.3 & 511,877 & 1.112889 \\
18 & 31741.09 & 480824.9 & 512,566 & 1.114388 \\
19 & 31708.9 & 481507.8 & 513,217 & 1.115802 \\
20 & 31678.45 & 482154.1 & 513,833 & 1.117141 \\
21 & 31649.54 & 482767.9 & 514,417 & 1.118413 \\
\hline
\end{tabular}

With first 2 years excluded from the points, the total energy usage shows a pretty good logarithm relationship with the number of operating years. The increasing energy usage indicates that the GSHP system is becoming lower efficient with running period. This is because the heat rejection is not equal to heat extraction from the ground.

Table 3 summarizes the R/E ratio for different locations. Even for the cities in severe cold climate region where space heating is dominant compared to cooling, the $\mathrm{R} / \mathrm{E}$ ratio is still larger than 1 , which indicates that for a typical office building, space heating can be partially satisfied by relatively large internal gain. Figure 2 shows the normalized energy usage with variation of time for Nanjing. 
Table 3. R/E ratio of the investigated office building for different locations.

\begin{tabular}{llllllllll}
\hline City & Nanjing & Harbin & Shenyang & Beijing & Jinan & Qiqihar & Guangzhou & Lanzhou & Chengdu \\
\hline R/E & 15.15 & 1.58 & 2.79 & 6.25 & 9.11 & 1.90 & 363.57 & 3.88 & 22.84 \\
\hline
\end{tabular}

The same parametric running was conducted for those different locations mentioned above. For Guangzhou as in Figure 3, which is located in warm winter area, the GSHP loop exceed the high limit, indicating that the current system is not sufficient in providing enough cooling to the building.

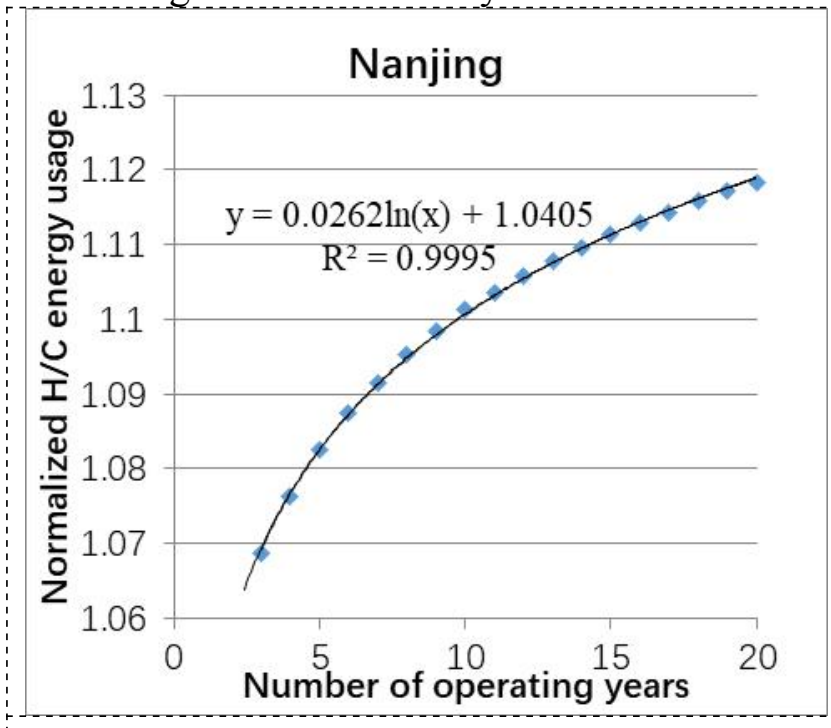

Figure 2. Normalized $\mathrm{H} / \mathrm{C}$ energy usage variation with operating years for Nanjing.

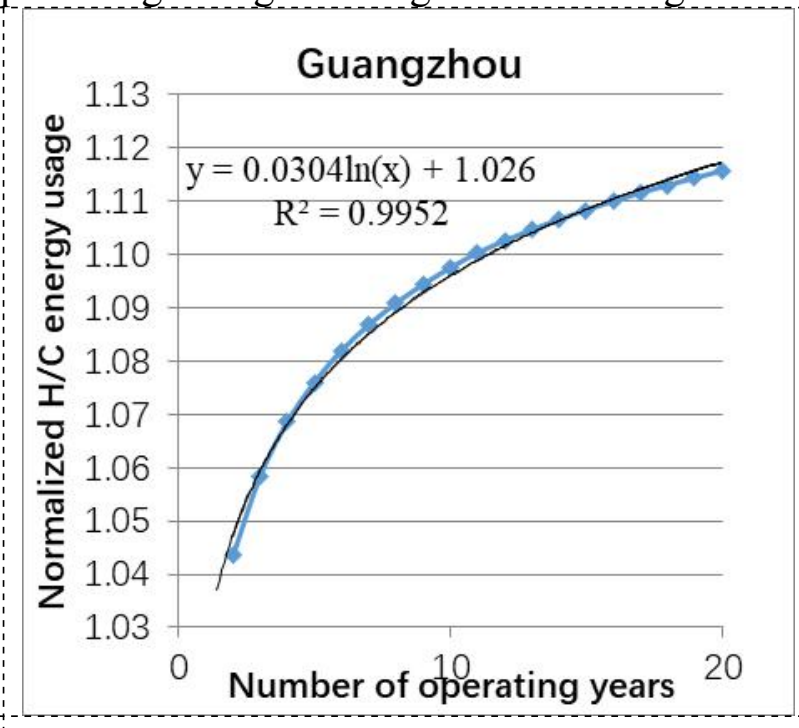

Figure 3. Normalized $\mathrm{H} / \mathrm{C}$ energy usage variation with operating years for Guangzhou.

Total GHX was increased to 50 instead of 30 . The R/E ratio for this city is more than 300 and the space conditioning usage increases rapidly with time. For such building, the life-cycle period will be much shorter if it's located in a warm area than in cold area. The impact of $\mathrm{R} / \mathrm{E}$ ratio on the life-cycle period of a GSHP system is the imbalance of heating and cooling load for different areas.

$$
\begin{aligned}
\text { Rejection } & =\text { Cooling load } *\left(1+C O P_{\text {cooling }}\right) \\
\text { Extraction } & =\text { Heating load } /\left(1+C O P_{\text {heating }}\right)
\end{aligned}
$$

To balance the heat gain and loss of the ground, R/E should be equal to 1 . Assume heating and cooling COP is close to each other we can get Equation (3).

$$
\text { Heating load }=\text { Cooling load } *(1+C O P)^{2}
$$

The ideal building for utilization of a GSHP system should satisfy such relationship of heating and cooling load. Since the R/E ratio or H/C load ratio can affect the life-cycle period of GSHP system dramatically, the incentive should differentiate the building from such aspect.

\section{Regression Analysis}

The simulation was extended to different cities located at different climate zones. For all of these locations, the normalized space conditioning energy usage has logarithm relationship with the total operating years as Equation (4).

$$
Y=a * \ln (t)+1
$$

Where $Y$ represents how many times of energy used in a year compared with the first year, $t$ represents the total operation time (years) of the system. a is a factor determining the energy consumption increment speed in the future years, which is defined as energy usage factor here.

For different cities, the R/E ratio is assumed to determine the factor "a". The regression of usage factor " $\mathrm{a}$ " and R/E ratio is as Figure 4. The two parameters show a relationship as Equation (5).

$$
a=0.011 * \ln \left(\frac{R}{E}\right)+0.0085
$$


The result for Guangzhou is excluded from the plot since it's way off the regression trend line. The reason is that more GHX units are installed for Guangzhou case to meet the cooling load, and such a result indicates that the regression can only valid for current GHX loop.

To verify the method, the system was assigned to a different building located in Wuhan and the energy consumption increasing with the total operation period is as Figure 5.

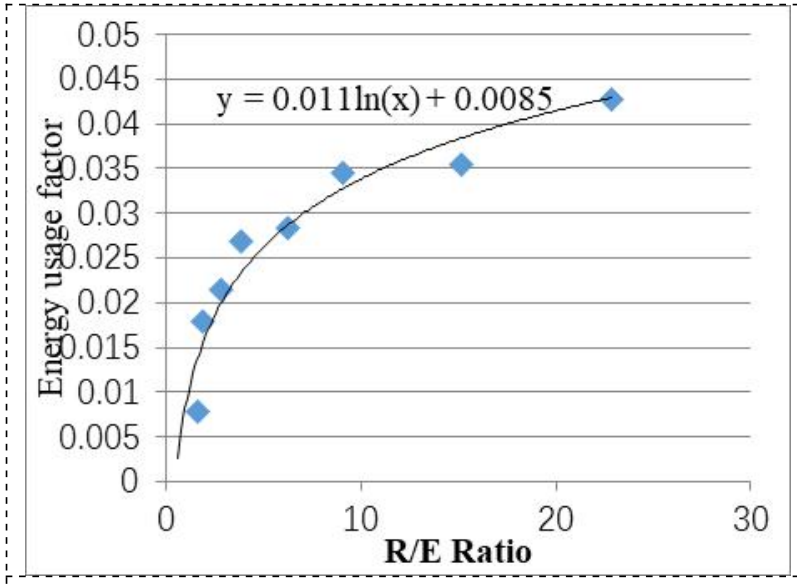

Figure 4. Plot of energy usage factor and R/E ratio.

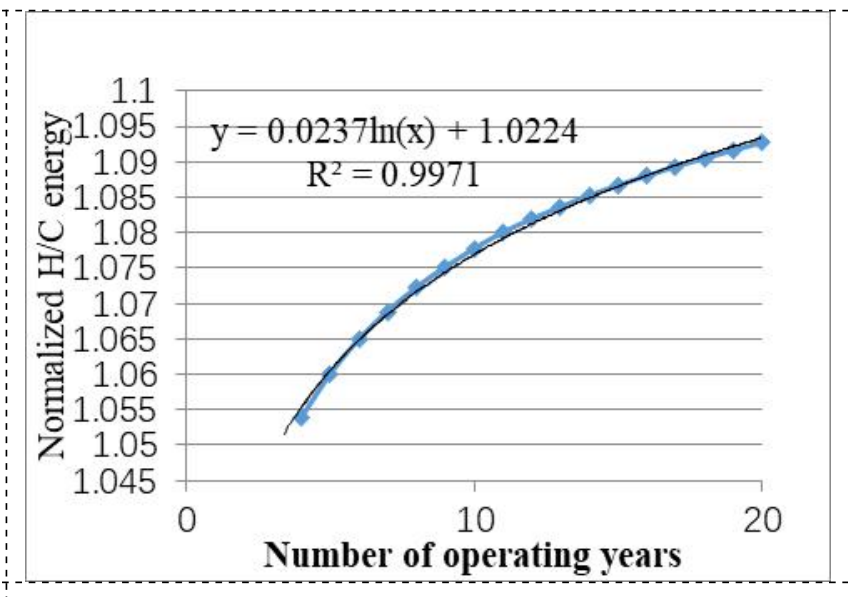

Figure 5. Normalized $\mathrm{H} / \mathrm{C}$ energy usage variation with operating years for Wuhan.

Here the $\mathrm{R} / \mathrm{E}$ ratio is 5.9 and the calculated energy usage factor $\mathrm{a}=0.028$ and the percentage error to the actual value $\mathrm{a}=0.0237$ is:

$$
(0.028-0.0237) / 0.0237 * 100 \%=18.2 \%
$$

\section{Conclusion}

A high-rise office building with GSHP system was simulated. It is found that due to the imbalance of heat ejection to and extraction from the ground, the space conditioning energy usage increase with total operating period along logarithm line. The speed of such energy usage increment is determined by the imbalance of $\mathrm{R} / \mathrm{E}$. A design guideline was recommended base on the $\mathrm{R} / \mathrm{E}=1$ to avoid the energy increasing from time to time. An analytical relationship between energy usage factor and R/E ratio was concluded and verified for current GHX configuration. For a typical office building, the heat ejection to the ground is easy to exceed the amount of heat extraction even in severe cold climate zone, which mean the current government supportive policy should give more credit to the location where space heating is a main issue or buildings which heating load is dominant.

\section{References}

[1]http://www.chinastakes.com/2009/11/pre-copenhagen-china-promises-40-emission-intensity-cuta-mission-impossible.html

[2] Wei Yang, Jin Zhou, Wei Xu, Guoqiang Zhang, Current status of ground-source heat pumps in China, Energy Policy, Volume 38, Issue 1, January 2010, Pages 323-332

[3] Lv, Y., Yang, L.P., Zhou, M., Mo, R., 2005. The ground source hot pump uses the survey report of the situation domestically. Construction and Design for Project 6, 5-10 (in Chinese).

[4] Yavuzturk, C., J.D. Spitler. 2001. Field Validation of a Short Time-Step Model for Vertical Ground Loop Heat Exchangers. ASHRAE Transactions, Vol. 107, No.1, pp.617-625.

[5] EnergyPlus Engineering Document: The Reference to EnergyPlus Calculations. US Department of Energy, 2004.

[6] Documentation for the DOE-2.2

[7] eQUEST Introductory Tutorial. Version 3.63. 